\title{
PRESENCIA DE SAUSSURE EN EL MUNDO HISPÁNICO (introducción)
}

\author{
José Polo \\ Universidad Autónoma de Madrid
}

\section{Lema}

«El único cambio de paradigma claro que ha habido, durante este siglo, en las disciplinas lingüísticas fue el proporcionado por el Curso, de Saussure, y él se murió sin estar convencido de ello» (Gregorio SALVADOR, «Escritores, lectores, críticos» [reseña al libro de Ricardo Senabre Literatura y público, Paraninfo, Madrid, 1987], en Saber leer [Fundación Juan March, Madrid], 30/1989, págs. 6-7, 6 la cita).

2. Presentación [texto redactado en 1987 como memoria explicativa de un proyecto científico para el que fue denegada la ayuda solicitada]

\section{$A$}

Cuando se habla de la trascendencia de la obra científica de este genial lingüista, considerado creador de la Lingüística Moderna, suele estudiarse al mismo tiempo la enorme influencia de su pensamiento por doquier. En los repasos geográfico-históricos saussurianos a que estamos acostumbrados, desfilan lustrosos algunos países, o algunos ámbitos culturales, presentados como adelantados en la investigación historiográfica de Saussure. Pues bien: uno de los que no aparece en primera línea en este respecto es España (o, en general, el mundo hispanohablante). Sin embargo, tal preterición - puesto que no se corresponde con la realidad - no debe prolongarse ya más.

*Departamento de Filología Española. Universidad Autónoma, Cantoblanco. 28049 Madrid. 
En efecto, mi sistemática indagación entre bibliográfica e historiográfica me ha llevado al absoluto convencimiento de que en nuestro ámbito ha sido bastante lo realizado en torno a Saussure y que, por consiguiente, la ausencia de los nombres de nuestros países se debe exclusivamente a desconocimiento, fronteras afuera, de esa labor científica tan temprana y fecundamente llevada a cabo. Los materiales que poseo y aquellos de cuya existencia puedo responder son lo suficientemente expresivos como para que pueda configurar un denso volumen alrededor de la figura de Saussure, mostrando con todo ello la gran riqueza textual y hermenéutica de nuestro ámbito cultural en torno al fundador de la lingüística moderna. Con ello espero dejar claro que muchas veces no es que España no se haya incorporado al desarrollo de la ciencia en el mundo (cosa a la que no me opongo como principio o en determinados campos), sino que, por diversas razones, no se ha llegado a conocer internacionalmente aquello que sí se ha realizado en nuestros respectivos países [en un trabajo de quien esto escribe, a medio plazo - Saussure en los últimos decenios - habrá ocasión de leer las contundentes y esclarecedoras palabras de G. Salvador al respecto].

C

Pues bien: desde hace mucho tiempo vengo rastreando, por diversos vericuetos, multitud de huellas científicas cuasiperdidas (véase, en el historial presentado, la sección de publicaciones) y esa labor va dando sus frutos: comienzan a aparecer «eslabones perdidos» de lo que algún día deberá convertirse en una historia general de las ideas lingüísticas en el ámbito hispánico. Mi sistemática pesquisición sobre fuentes y desarrollos historiográficos creo que me sitúan en una buena perspectiva para acometer con garantía un trabajo científico de esta naturaleza. Ya en mi libro Epistemología del lenguaje e historia de la lingüística. Momentos de su desarrollo bibliográfico en el ámbito hispanohablante (Gredos, Madrid, 1986) señalaba'(pág. 68, ficha 95-b) a manera de contexto del proyecto de ahora: «Hace poco —otro ejemplo- he estado calando una importante edición del CLG [Curso de lingüística general, Saussure] y he visto, en la parte en que se informa de la repercusión de ese clásico en el ámbito hispanohablante, las escasas líneas, los paupérrimos datos que parecen conocerse de dicha proyección en nuestro medio. No hablaré aquí tampoco de la parva cosecha registrada, en este respecto, en una bibliografía saussuriana de resonancia internacional [la de Koerner]; mostraré todo ello, con la atención debida, en un trabajo sobre Saussure en el mundo hispanohablante que tengo en preparación» [véase en seguida 3].

\section{$D$}

Espero, pues, se comprenda la importancia de este proyecto, el buen momento «historiográfico» que vivimos dentro de la lingüística y el hecho de que el historial de quien va a realizarlo muestra a una persona capaz de llevarlo a buen puerto. 


\section{Testimonios complementarios}

Para dejar redondeada la idea apuntada del escaso conocimiento exterior de la labor saussuriana hispánica, voy a transcribir dos pasajes de sendos trabajos propios: 1) «El Saussure de Koerner (nota de presentación de la edición española)», en Archivum [Oviedo], XXXVI-XXXvII//1987-88, págs. 237-250, 243/\$12 la cita; 2) «Textos de lingüística y visión normativa. A propósito de la última edición en español, 1983, del Curso de Saussure», en Anuario de Estudios Filológicos [Universidad de Extremadura, Cáceres], xII/1990, págs. 311-330, 313/§2-1 la cita.

\section{1}

Como ocurre normalmente con los estudiosos de la lingüística general que alguna vez se acuerdan de lo hecho en tierras hispanas, es más que parva la cosecha habida. Así, en la pág. 95, nota 24, se refiere el autor a un trabajo de M. Mourelle de Lema sobre la Escuela de Ginebra y no puede por menos de criticarlo sin rodeos. Ahora bien: hay bastantes más cosas que ese estudio en nuestro lar científico. De todos modos, no siempre o no toda la responsabilidad de situaciones como la acabada de mencionar es del autor que cita —en este caso, Koerner-; obedece a diversos factores, alguno de los cuales tiene que ver, sin duda, con fallos en la base científico-comunicativa de nuestro medio social.

En Reseña bibliográfica..., apartado 8, Repercusión del CLG en los diversos países, al referirse a los de lengua española, págs. 381-382, apenas son doce líneas las dedicadas a mencionar los trabajos en que se tiene en cuenta especialmente a Saussure. Yo mismo poseo materiales — base de un proyecto a medio plazo — para multiplicar con creces esas paupérrimas doce líneas. No debe, sin embargo, achacársele toda la responsabilidad a Mauro. Las dificultades de comunicación científica son grandes en casi todo el mundo en nuestro campo, pero mucho, infinitamente más, en algunos países (España, por ejemplo; y los hay peores); y ello influye en alguna medida en la dificultad de que lo hecho por nosotros sea conocido fuera... Es mucho pedir cuando ni dentro de nuestras fronteras funciona mínimamente el flujo de información. La casuística, grotesca, resultaría, naturalmente, «no creíble»: vergonzante.

\section{Amado Alonso}

a) En 1945 publica nuestro autor, en Editorial Losada, su traducción del Cours de Saussure: Curso de lingüística general. Además de la versión, Amado Alonso anota la obra y le pone un espléndido «prólogo a la edición española» (págs. 7-30), simultáneo prácticamente con su artículo «La doctrina linguiística de Ferdinand de Saussure», en $L a$ Nación [Buenos Aires], 12 de agosto de 1945 (convendría llevar a cabo un cotejo entre ambos escritos; el realizado por mí, con carácter provisional, muestra diferencias dignas de ser tenidas en cuenta en una edición definitiva en posible volumen de recogida de sus estudios historiográficos). Ahora, en las fichas que siguen, mencionaré algunos trabajos que hablan de ese clásico prólogo de Amado Alonso.

b) En Problemas y métodos de la lingüística, de Walther von WartBurg (tr. de Dámaso Alonso y Emilio Lorenzo; anotado para los lectores hispánicos por el primero 
de estos autores: csic, Madrid, 1951; reimpresión: 1991), en la pág. 8, nota 2, nos dice Wartburg que para esa parte, lengua-habla, sigue en lo esencial la exposición de Saussure; y el anotador, Dámaso Alonso, completa: «Véase ahora la traducción española de Amado Alonso[...], con excelente prólogo del traductor». Sirva esta cita como mero recordatorio de los muchos elogios breves sobre la labor saussuriana de Amado Alonso. Para la contribución, en esta zona de estudio, del propio Dámaso Alonso, remito, por un lado, al artículo que antecede a este en el presente número de la revista - «Traducciones al español del Curso de Saussure»-y, por otro, a un trabajo próximo, «Lectura del Curso de Saussure por Dámaso Alonso»; también habrá un volumen con todos los materiales saussurianos de nuestro poeta, lingüista y filólogo.

c) Rudolf ENGLER publica (en Kratylos, IV-2/1959, págs. 119-132) su artículo «CLG und SM: eine kritische Ausgabe des Cours de linguistique générale» (con SM se refiere, claro está, a las Sources manuscrites [...] de Robert Godel, 1957). En la pág. 124 anota el renombrado estudioso de Saussure: «Wir haben in den SM die Antwort auf die Fragen, die Amado Alonso auf S. 29 y 30 seines Prólogo a la edición española des Curso de lingüística general (Buenos Aires 1945) formulierte». Luego reproduce el anunciado texto del autor hispano:

[No pensemos que con esto arrinconamos la lingüística de Saussure y abrazamos otra tendencia. Estamos esforzándonos en presentar la doctrina misma del Curso y en alargar sus líneas por donde y hasta donde la crítica ha comprobado]. ¡Quién sabe hasta dónde las habría prolongado o hacia dónde rectificado el mismo Saussure si la muerte le hubiera dado el tiempo que su conciencia tan escrupulosa requería, si él mismo hubiera por lo menos escrito su libro! Y sobre todo, si, escrito por él y publicado, hubiera tenido ocasión de participar en las pruebas y contrastaciones a que la crítica ha ido sometiendo sus doctrinas. Casi al mismo Saussure podemos acreditar todas las superaciones de sus teorías aquí apuntadas: la nueva fonología, aunque explícitamente negada en el Curso, está en él implícitamente postulada; y sus tres más devotos discípulos patrocinan las otras rectificaciones: Meillet, vivificando la historia linguística con la historia de la civilización; Bally, insuflando la vida real, individual y social, en el funcionamiento del sistema [E. omite nota], y Sechehaye, reconociendo que la irreducción de las antinomias se salva centrando la lingüística en la omnipresente «habla» y no en la «lengua».

Bien: sirva la mención de Amado Alonso por parte de Rudolf Engler como muestra de muchas otras que, sin duda, cabría espigar en trabajos escritos en lengua distinta de la española.

d) Hortensia ViñEs RuEda presenta oralmente en 1979, en un congreso, su comunicación «Acerca de las ideas lingüísticas de Amado Alonso (Prólogo al Curso [...] de Ferdinand de Saussure)», cuyo resumen se publica en Revista Española de Lingüística, x-1/1980, pág. 246. Aparece el texto íntegro en Fontes Lingvae Vasconvm [Pamplona], 35-36/1980, págs. 223-251. Tras una breve introducción general a la obra de Amado Alonso, comenta, en una primera parte, ese estudio prologal y luego lo reproduce creándole epígrafes, rótulos, al desfile del pensamiento del investigador hispano- 
-argentino. Positivo resulta el propio hecho de la atención al conjunto del famoso Prólogo.

e) Bertil Malmberg saca a la luz, en Lingüística Española Actual (v-1/1983, págs. 131-136), su trabajo «Amado Alonso, intérprete del Cours de Saussure». Buen conocedor de lo esencial de la lingüística en el medio hispánico (en más de un estudio ha hablado con acierto de la concepción integradora de lengua/literatura/historia de Meriéndez Pidal), el investigador sueco pone de relieve la importancia del prólogo de Amado Alonso, su lugar dentro del desarrollo internacional de la historiografía lingüística.

f) Julio García Morejón (Límites de la estilística. El idearium crítico de Dámaso Alonso, Facultad de Filosofía, Ciências e Letras de Assis, 1961, pág. 31): «La lingüística general tuvo en él [en Amado Alonso] uno de sus más fervorosos adeptos e intérpretes. Su prólogo a la traducción del Cours de Saussure [...] es una obra maestra de interpretación de las doctrinas del maestro ginebrino, hasta el punto de transformar a la edición española de esta obra en la más importante para la comprensión de las ideas saussureanas».

\section{Un trabajo fecundo}

a) Me refiero al breve pero instructivo artículo de Santiago Mollfulleda «La introducción de la doctrina saussuriana en España», publicado en Revista Española de Lingüística, XII-2/1983, págs. 241-247; un resumen había aparecido ya en la pág. 160 de este tomo (la primera exposición pública, oral, en diciembre de 1982: simposio). Datos de gran interés se desprenden de una lectura atenta del escrito. Estamos frente a La Paraula, de Ivón L'EsCop, seudónimo del P. Ricard ARAGó I TuRón, publicada por Editorial Polígrafa, Barcelona, en 1921. En ella se encuentran numerosas referencias directas al Curso de Saussure, etc.

b) En la pág. 244 anota el prof. Mollfulleda: «[...] la más temprana exposición del Cours [...] realizada en nuestra patria». Ya al final, pág. 247, cierra el trabajo con estas palabras (matizadas con respecto a la cita anterior): «Por todo ello, creemos poder atribuir a nuestro autor el honor de haber sido uno de los primeros en exponer en España, extensa y precisamente, la doctrina del gran renovador de la lingüística moderna». En esta obra hay, además, constantes referencias a otros estudios importantes de la época (compárese, en el epígrafe siguiente, Juan M. Dihigo, «universalista nato»).

c) Entre las págs. 244 y 245 de su artículo nos presenta el Dr. Mollfulleda los temas saussurianos que atrajeron especialmente la atención del autor de La Paraula: 1) oposición lengua/habla; 2)lengua= sistema de valores preestablecido; 3) la lengua se caracteriza por el carácter negativo de sus elementos; 4) la lengua es un sistema de signos, no una simple nomenclatura; 5) el signo lingüístico no une una cosa y un nombre, sino un concepto y una imagen acústica, un significante y un significado; 6) el signo lingüístico es arbitrario e inmutable; 7) todo en la lengua se altera y se transforma, tanto 
los sonidos como las palabras y los nexos gramaticales; 8) la analogía contribuye a modificar la estructura de los signos a pesar de tener por objeto regular y nivelar las irregularidades producidas por la fonética; 9) «Encontramos también en la obra de Aragó recogido el paralelo con el juego de ajedrez; alusiones expresas a la fonología y a los fonemas; a la idea de la lengua como forma, etc., etc.».

d) En el resumen nos había dicho el investigador mencionado: «Así, en La Paraula se exponen, citando en la mayoría de los casos textualmente la primera edición (1916) del Cours, los temas más característicamente saussureanos». Enumera 1) la oposición lengua/habla; 2) la naturaleza del signo linguiístico; 3) la oposición significante/ significado; 4)la lengua como sistema; 5) la lengua como forma; 6) la arbitrariedad e inmutabilidad del signo; 7) el cambio lingüístico; 8) el carácter social de la lengua. «También recoge Aragó las ideas de Saussure sobre los puntos siguientes: economía lingüística; sustrato; imposibilidad de los sinónimos perfectos; relación lengua-razapueblo (compárese Unamuno); crítica de las gramáticas tradicionales; oposición lengua escrita/lengua hablada, etc. Es asimismo notable la alusión expresa a la fonología (páginas 111 y 133) y el uso técnico y preciso del término estructura».

e) He reproducido las dos listas de temas saussurianos sobre los que se fijó el autor de La Paraula porque hay pequeñas diferencias - no contradicciones - entre los dos bloques enumerativos y nos interesa tener la visión más amplia posible pensando en si se trata de los temas que aparecen por doquier en la obra por antonomasia de Saussure, si son aquellos de los que ningún lector atento puede escapar; lo que podría rastrearse comparando numerosos comentarios sobre el Curso (véanse, por ejemplo, los dos trabajos anunciados en 4-ab).

f) También interesa tener muy en cuenta la idea apuntada por el prof. Mollfulleda sobre las posibles causas de que La Paraula pasara prácticamente inadvertida: su estilo barroco y apasionado, sus abundantes metáforas, etc., junto a factores de sociología de la ciencia que él prudentemente insinúa. En más de un trabajo de quien esto escribe ha habido también referencias al hecho de cómo un estilo de exposición determinado ha podido contribuir a la minusvaloración -injusta desde luego- de la obra de esos autores «coloquialistas», etc.

g) Voy a citar ahora unas palabras (pág. 247) del autor del artículo del que vengo ocupándome en este epígrafe, uniendo con ello esta parte final con los dos fragmentos que transcribí al principio: «[...] Y La Paraula se ha convertido en pura arqueología lingüística - lo que no es mérito despreciable - a pesar de tratarse, insisto en ello, de la primera obra publicada en España que contiene prácticamente, como hemos visto, todos los conceptos fundamentales de la gran obra de Saussure. Y esto es suficiente para que podamos reivindicar para ella el honor de haber sido la pionera o, si se prefiere, la adelantada, en nuestra patria, de los estudios que iban a dar un giro copernicano a la lingüística general».

h) Por el artículo del prof. Mollfulleda sabemos también que en 1933 P. Fabra habló de cuestiones lingüísticas en las que las referencias a Saussure no estaban ausentes. Si 
ahora, finalmente, resumimos con fechas datos varios manejados por dicho investigador, tendríamos la siguiente tabla cronológica:

1916: fecha de publicación del Cours;

1917: en el t. Iv de Revista de Filología Española, pág. 85, ficha 5024, aparece la obra de Saussure;

1921: La Paraula, de Ivón l'Escop;

1922: de nuevo RFE: t. IX, pág. 202, ficha 11403:

Recueil des publications scientifiques de Ferdinand de Saussure (C. Winter, Heidelberg, 1921);

1933: Pompeu Fabra presta atención, aunque no tan declarada y sistemática, a Saussure;

1945: Amado Alonso traduce, anota para lectores hispanohablantes y prologa la obra clásica de Saussure: Cours de linguistique générale $\left(1916,{ }^{2} 1922,{ }^{3} 1931\right)$.

Establecido ya ese cuadro cronológico como punto de anclaje imprescindible antes de seguir adelante (en este mismo trabajo y en lo anunciado atrás, 4- $b$ ), pasamos al siguiente epígrafe...

\section{Juan Miguel Dihigo (1866-1952)}

a) Lo afirmaré ya: el cubano universal Juan M. Dihigo fue el primero que, en el ámbito de la lengua española, escribió sobre el Curso de Saussure. Aunque sobre la generosa figura de este sabio hispano existe, cuando menos, un estudio de conjunto, más bien somero (véase más adelante f), su talla internacional está pidiendo a voces que se prosiga la tarea investigadora en torno a su muy amplia obra. No quiero, dado el peligro de quedar atrapado por estímulos mil, desviarme de la intención de ahora (no doy, pues, referencia alguna de sus trabajos en general o de sus relaciones con investigadores «de todo el mundo»).

b) En el vol. XVII-3/1913, págs. 190-193, de Revista de la Facultad de Letras y Ciencias [Universidad de La Habana], dentro de la sección Necrología, publica nuestro autor «Fernando de Saussure». Hermosa nota: han ido desapareciendo en los últimos tiempos otros grandes estudiosos; importancia de la obra de Saussure (aun sin ser suficientemente conocida); seguidores de Saussure. A propósito de una reforma en los planes de estudios de letras en su universidad, escribe Dihigo a Saussure y este le contesta con fecha 16-XI-1906 y le recomienda que deje para el final de la carrera las generalidades, que en los primeros cursos interesa el contacto con los hechos concretos...; es decir, que por esa época asomaba claro el pensamiento histórico-comparativo, «positivista», de Saussure. En la obra mencionada más adelante, f, leemos (pág. 161): «En la misma, Saussure le contesta que su plan es bueno, puesto que, a su entender, es mucho mejor dejar para el final las generalidades, y comenzar por los métodos que hacen posible estudiar las lenguas indoeuropeas, el griego o el latín, o las lenguas romances». 
c) En el vol. xxIv-1/1917 de la misma revista, en la sección Notas Bibliográficas, publica Dihigo, págs. 96-97, su reseña al flamante Cours de linguistique générale (1916). Escrito más apagado que el anterior, menos vibrante; pero persiste su admiración por el maestro ginebrino y se fija en algunos conceptos: sincronía/diacronía, etc.

d) En la misma revista, vol. xxxiv/1-2/1924, págs. 154-169, publica «Algunos grandes pensadores de la ciencia del lenguaje»; Saussure: págs. 164-165.

e) En el vol. II/17-18/1938, págs. 237-262, de Universidad de La Habana publica nuestro autor «Cromitos lingüísticos. Los grandes maestros» [con proyección de las efigies originalmente]; Saussure: págs. 252-253.

f) Véase ahora, de Rafael MARTíNeZ, Juan Miguel Dihigo: gran linguista cubano, Editorial Letras Cubanas (colección Espiral), La Habana, 1983, 244 págs. «Su valoración de Ferdinand de Saussure»: págs. 158-164. De gran utilidad la investigación del prof. Martínez, no obstante su carácter somero considerando la magnitud de la obra del sabio cubano; pero, de entrada, no se puede aspirar a lo máximo en un proyecto tan complejo.

g) Finalmente, recomendaría se hiciese un esfuerzo por recuperar la correspondencia Dihigo-Saussure (sobre todo la que supongo en situación más aleatoria: la que recibió el polígrafo cubano). Si se lograse tal propósito, cabría pensar en la publicación de un volumen que contuviese los escritos saussurianos de Dihigo, atrás fichados, junto con esa correspondencia científica. Dejo de lado, como antes he dicho, el tratamiento historiográfico de otros grandes de la ciencia del lenguaje en el universo científico de Juan M. Dihigo (queda para otra oportunidad).

\section{Final}

A la vista de lo presentado en los dos últimos epígrafes, convendrá recomponer —despedida del presente trabajo y preparación del terreno pára el anunciado en 4-bla tabla cronológica de 5:

1913: Dihigo (nota necrológica sobre Saussure);

1916: aparece el Cours;

1917: queda fichada esa obra en $R F E$; reseña de Dihigo en Cuba;

1921: La Paraula, de Ivón L'Escop;

1922: ficha de Recueil de Saussure en RFE;;

1933: Pompeu Fabra y Saussure.

1945: Amado Alonso y Saussure.

Fechas vendrán que nos obliguen a reajustar, enriqueciéndolo, ese orden: con todo su derecho y con «fuerza arrolladora» entrarán en juego 1930, 1934 y 1950: DÁmAso Alonso... 